\title{
Identification of Factors Influential in Policy Making and Presenting a Combined Model of Iran's Policy-Making
}

\author{
Lotfolah Forozandeh Dehkordy ${ }^{1}$, Fatemeh Shakhsian ${ }^{2}$, Khaled Nawaser $^{3}$, Seyed Mahdi Vesal ${ }^{4} \&$ Azadeh Kamel $^{5}$ \\ ${ }^{1}$ Faculty of Management, Tarbiat Modares University, Iran \\ ${ }^{2}$ Research Scholar in Business Management, Payam-e-Noor University, Iran \\ ${ }^{3}$ Marketing Management (SIOM) \& International Business (AIMS), University of Pune, India \\ ${ }^{4}$ Department of Management, University of Nooretouba, Iran \\ ${ }^{5}$ E-business management, Industrial Management Institute (IMI), Iran \\ Correspondence: Khaled Nawaser, Allana Institute of Management Sciences (AIMS), University of Pune, \\ Maharashtra, India. Tel: 91-800-717-4492. E-mail: khalednawaser56@gmail.com
}

Received: June 2, 2013 Accepted: July 17, 2013 Online Published: July 24, 2013

doi:10.5539/jsd.v6n8p118 URL: http://dx.doi.org/10.5539/jsd.v6n8p118

\begin{abstract}
Modeling is a modern concept that enables the audience to analyze and understand components. Policy making models can describe complexity of what happening in real world in a simple and conceivable form. These models are considered as tools for clarifying thinking about policies and each one examines this issue with a special approach and from a specific point of view. In this article, it is attempted to present the most prominent policy making models collected by library study method, their effective factors are identified and the combined model of policy making in Iran is obtained based on relationships between these factors by interpretive structural modeling method using views of the experts. The results illustrates that the Cost-benefit analysis, political currents in society, previous decisions and social influence and power are the most influential factors in policy making.
\end{abstract}

Keywords: policy making, policy-making models, combined model, interpretive structural modeling

\section{Introduction}

No decision maker makes decision in vacuum. A decision usually appears through a complex environment in which many factors are involved. As Donald K. Hansen states: "decision makers (especially at national level) are in a very complex environment that encounters many obstacles including international law, various regulations, institutions and ideologies. Even if these factors are not considered so much as obstacles, a policy maker encounters issues like bureaucracy, influential figures, media, parliament and cognitive limitations". David Brooks states: "a policy maker has general goals in mind but unknown path ahead in which everything is obscure" (Edwards, 1996). Determination of priorities and distinguishing between optimal and satisfactory results is sometimes very challenging and how it must be addressed varies with each particular case.

Modeling is a modern word that enables audience to analyze and understand components. Policy making models can describe complexity of what happening in real world in a simple and conceivable form. These models are considered tools for clarifying thinking about policies and each one examines this issue from a specific point of view (Boer et al., 2011). These models also can be effective in identification of the following factors: identification of the most important aspects of policies, concentrating on obvious characteristics of political thought, drawing a distinction between important and unimportant events in policy making process, describing policies and predicting their results (Cockrel, 2002). Some of these models have rationalism approach (from totally rational to combined models) and others follow realism approach (Gholipour, 2008), that in fact indicates attitude and logic of decision makers.

As mentioned earlier, each proposed model addresses policy making concept from a specific aspect and particular point of view. In order to make these models more applicable in general policy makings of country, this articles tries to review the most important models proposed in policy making area, identify the most 
important factors constituting these models, and obtain a combined model for policy making in Islamic Republic Regime.

\section{Policy Making Models}

In a general categorization, models proposed in policy making area can be categorized in two general groups based on "decision making manner" and based on "the decision maker". First, models based on decision making manner are addressed:

\subsection{Models Based on Decision Making Manner}

\subsubsection{Process Model}

One of the most applied models in general (public) policy makings is process model. This model focuses on detection of pattern of activities or processes and includes the following steps: problem determination, presenting various solutions, legitimizing a solution, implementation, evaluation. Proponents of this model believe that researchers should focus on strategy making process instead of nature of strategies. This idea helps us find manner of decision making and strategy making (Clift, 2003; Rabiee \& Givrian, 2005; Alvani \& Sharif zadeh, 2008).

Process model was extended by Osimo (2011) in form of three loops: policy making process model was in the middle loop, tasks to be done in each step were in the middle loop and finally, tools that should be used in each step were in the outer loop.

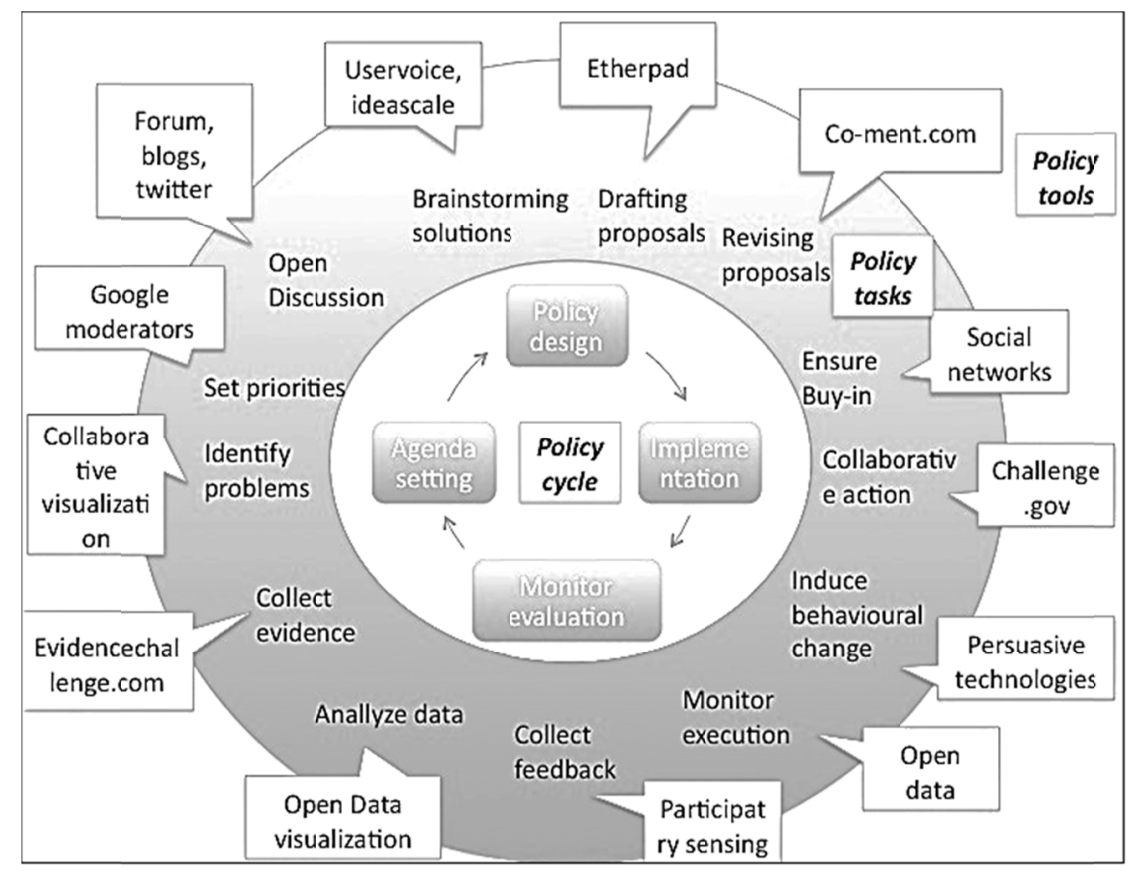

Figure 1. Extended (three-loop) process model (Osimo, 2011)

In a range from rationalism to realism, Rational Model to Gradual Changes Model can be considered:

\subsubsection{Rational Model}

In this model proposed in rationalism approach, the aim of specifying strategies is to maximize social benefit. Therefore, governments should choose strategies whose benefits are more than their costs. This model has two main guidelines: first, among various strategies, strategies whose costs are more than benefits should be avoided and second, decision makers should choose those strategies that have most benefit compared to costs (Sabatier, 2007; Boulanger, 2005; Rabiee \& Givrian, 2005; Alvani \& Sharif zadeh, 2008).

\subsubsection{Satisfactory Model}

The aim of this model is to find a satisfactory solution in current conditions rather than the best way. Limitations of sources, time and information and insight of manager and decision maker often leave no other choice for 
decision making in this model. In this model, sufficiently-good solutions are preferred to maximizing goodness (Howlett et al., 2009).

\subsubsection{Gradual Changes Model}

This model considers public (general) strategy as continuance of previous activities of government with minimal modification. It assumes that decision makers do not examine all current and proposed strategies every year. It is why this model is considered a conservative model in public policy making and is focused on past programs and policies and designs new strategies based on this programs (Wyner, 2011; Alvani \& Sharif zadeh, 2008). Public budget and budgetary planning is recognized as a well known strategy or law based on Gradual Changes model (Rabiee \& Givrian, 2005).

\subsubsection{Exploratory-Innovative Model}

It is a modified rational model whose aim is minimal optimization. In other words, finding solution is based on satisfactory approach and is performed through trial and error. This model (like artificial intelligence) is more compatible with reality world. In exploratory-innovative planning, a simple principle is considered and comparisons are done continuously and true and false answers are determined (Colleti \& Murchison, 2002; Tickell, 2008).

By defining policy making process as a systematic process, the following models are taken into consideration:

\subsubsection{System Model}

One of models that have found wide application is system model which considers strategy as a reaction of system to forces it receives from environment. Here, we deal with four main concepts: inputs which are demands and supports from society, outputs which are a set of public policies and decisions resulted from system, political environment which refers to conditions or events out of borders of system and, finally, feedback which refers to the effects of system's programs and policies on the environment (Weible et al., 2004; Alvani \& Sharif zadeh, 2008; Rabiee \& Givrian, 2005).

\subsubsection{The Input-Output Model (I/O Model)}

The Input-Output Model is considered primary analytic tool for obtaining "instant presentation" of policy making process. The basis of this model can be seen in David Easton's work. Easton is a famous researcher and scientist in political sciences who introduced basic model in 1965 to describe formation of policies based on a set of needs and creation of new needs resulting from it. This model can be used in every organization with minimal changes (Alvi \& Gvosdev, 2010).

INPUT-OUTPUT MODEL

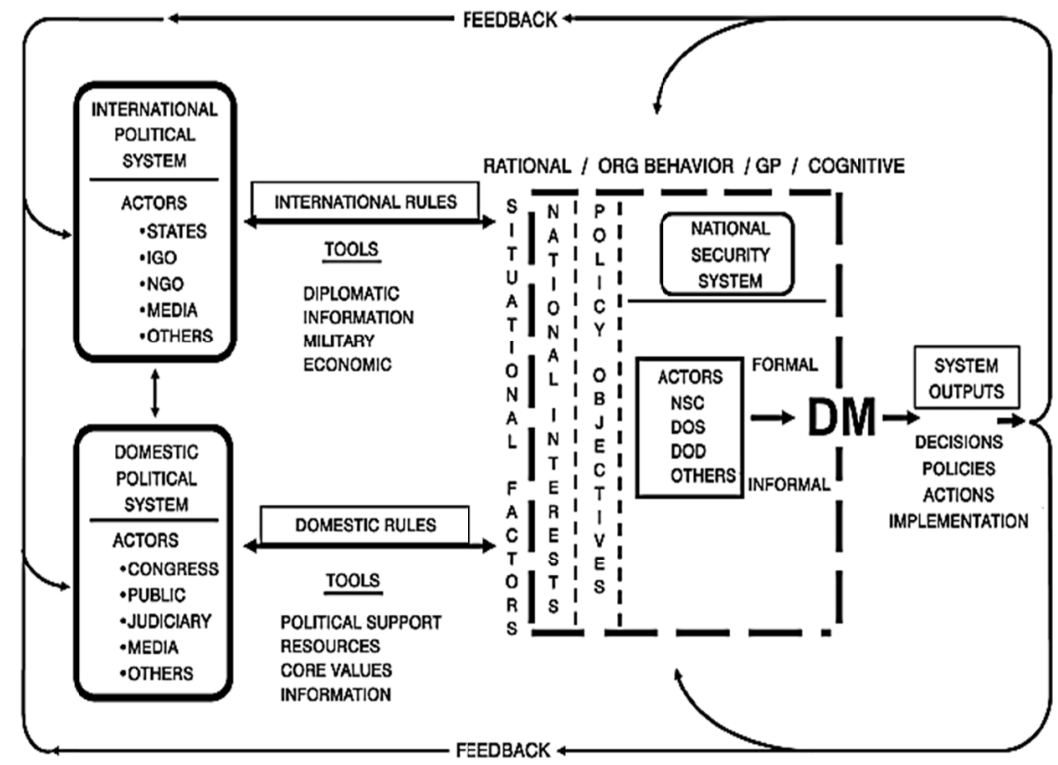

Figure 2. The Input-Output Model (Alvi \& Gvosdev, 2010) 


\subsubsection{Modern Policy Making Model}

This model, which was obtained by evaluating 130 case from public sectors of European Union (19 departments), states that considering conditions societies are encountering in $21^{\text {st }}$ century, a policy making model should include 9 main elements: looking to the future, looking outside, innovation, flexibility and creativity, reason-centeredness, comprehensiveness, linking all process components as a whole, revision, and learning lessons (Bullock et al., 2001).

\subsubsection{The Organized Disorder Model}

According to this model, public strategy is a result of strike of three currents: problems, policies and strategies. First current is problems which means an issue or phenomenon should be expressed as a problem among a group of people and attract their attention (Birkland, 2011). In this current, the problem should be defined and its solutions should be presented. Second current is political current. The important issue is governmental agenda in which various problems are entered. Various issues affect determination of agenda, including national spirit, participants' view, characteristics of government etc. that can influence how a problem is considered. Third current is strategies current in which different options enter agenda and strategy makers make decision on the basis of these various options presented. Therefore, policy making in this model is the result of strike of three currents: problem, policy and strategy. This model can be considered one of the most suitable models of strategy making in developing countries due to its presuppositions (Sabatir, 2007; Leach \& Sabatir, 2005).

\subsubsection{The Public Selection Model}

Economy studies behavior in marketplaces and assumes that people seek their private interests, while political science studies behavior in public area and its presupposition is that people seek public interests. But the Public Selection view questions this assumption and believes all players in policy area, like in market, try to maximize their own individual interests. This model considers governmental strategy and policies as a result of collective decision making by interested individuals and individual interests are considered the priority of all political activities (Sabatir, 2007; Rabiee \& Givrian, 2005; Alvani \& Sharif zadeh, 2008).

\subsubsection{Stages of Decision Making Model}

This model is also called "competitors' activity" model. The specific property of this model is its attention to the important role of opposite forces. In all stages of policy making, competitors make some steps in parallel: creating mutuality, presenting opposite suggestions (alternative), identifying authorities, developing mutuality, presenting alternative suggestion. The final stages of policy making are: 1) validating decision, 2) implementation and 3) evaluation (Cockrel, 2002).

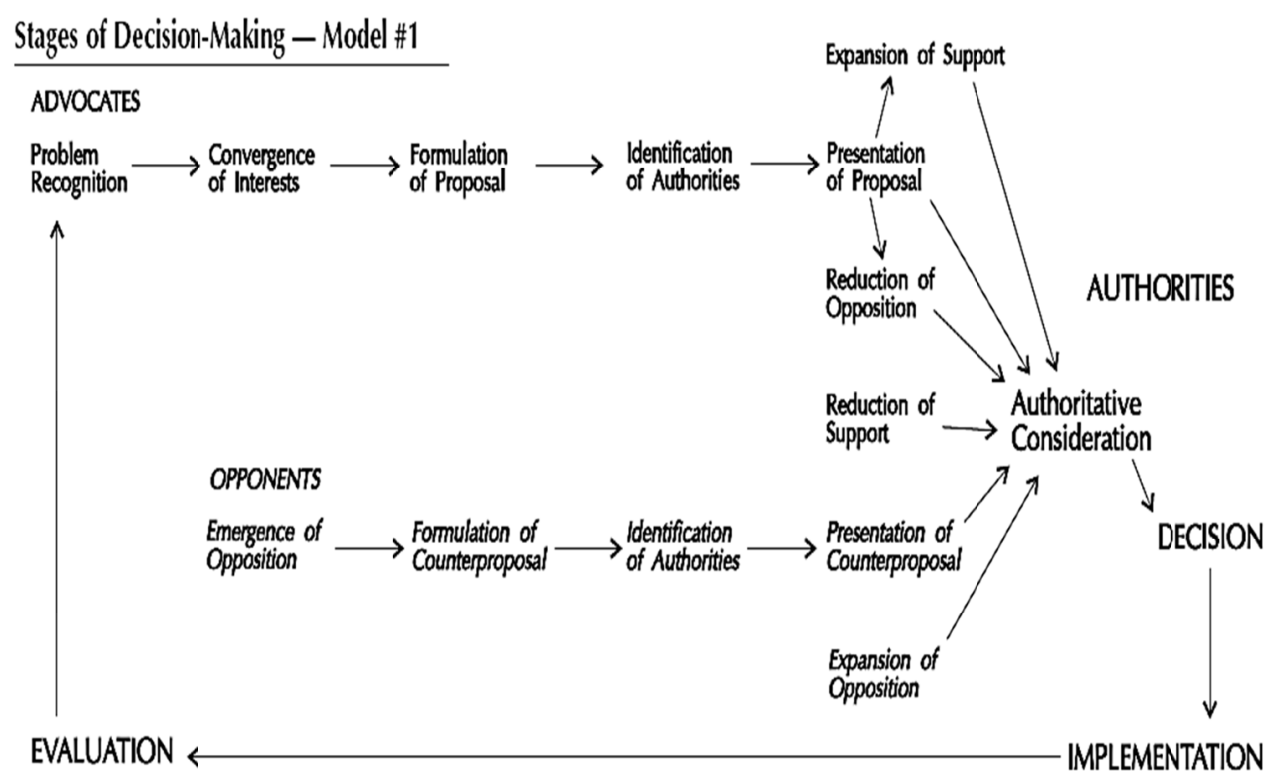

Figure 3. Stages of decision making model (Cockrel, 2002) 


\subsection{Decision Maker-Based Models}

\subsubsection{Entity Model}

In this model, public strategy making is a result of performance and interaction of various public entities in society. Strategies induce legal and formal power because they have governmental origin (Rabiee \& Givrian, 2005; Alvani \& Sharif zadeh, 2008).

\subsubsection{Social Decision Making Model}

Social decision making refers to gathering of two or more citizens of society for making a decision which benefits them. This community can consist of a small council or an international cooperation organization. In social strategy making model, the main issue is not obtaining political agreement and compromise, but emphasizing understanding different view, experiences, social and technical knowledge, creating and enhancing common responsibility.

This model goes beyond other models and by considering social and philosophical considerations, enables manager to resolve public problems with a better understanding of public management world. Social decision making process is of three types: process of direct selection of citizens, indirect decision making process, and combined selection process (Alvani \& Saharif zadeh, 2008).

\subsubsection{Citizen-Oriented Model}

This model is focused on citizens' needs as the most essential approach of social decision making and considers citizens as policy making coworkers. Bu extension of communications and information technology, cyber space can be considered as a new geographic dimension which facilitates maximum participation and cooperation of citizens in decision making (Keskinen \& Kuosa, 2005).

This model can be coordinated with "Conceptual Electronic Democracy Model" and "IT Network Model" and together they can be used for expression of a concept or idea (Baumfeld et al., 2002).

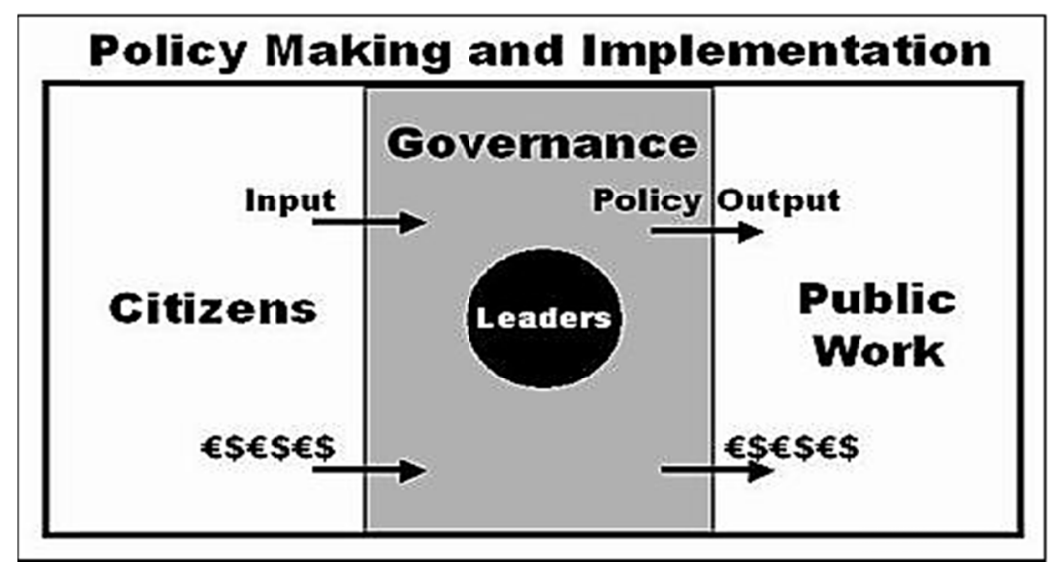

Figure 4. Citizen-oriented model (Clift, 2003)

\subsubsection{Group Model}

According to this model, it is the interaction between different groups that forms a policy or strategy. Indeed, groups are a bridge between individuals and government and policy is a form of struggle between different groups for influencing governing strategies. Political system resolve this conflict by following methods: respecting game rules in conflicts, using agreements and creating balance among groups, approving public strategies and policies, implementing these agreements and policies. According to this view, public strategy in each stage is obtaining balance in group conflicts. This balance is determined based on relative influence of each of interested groups (Alvani \& Sharif zadeh, 2008).

The following models are subset of Group Model:

\subsubsection{Elites Model}

This model states that in society, elites form votes and views of people in form of public strategies and public strategy leads to preferences of elites (Alvani \& Sharif zadeh, 2008). Among certain and important actions taken 
by political elites of Iran for specifying issues in order to make changes, are change and implementation of reforms in the constitution and subsequently creating an entity named "System Expediency Recognition Council". Role of political elites of Iran in public strategy scope is more sensible and evident due to lack of important and influential elements and groups in strategy making and law making (Rabiee \& Givrian, 2005).

\subsubsection{The Iron-Triangle Model}

The origin of this model is in policy making manner of agriculture sector in past few decades in which executive power, legislative power and pressure group of landholders determined policies. Over time, this has been used in various industries including pharmacology, transportation, military, housing etc (Cockrel, 2002).

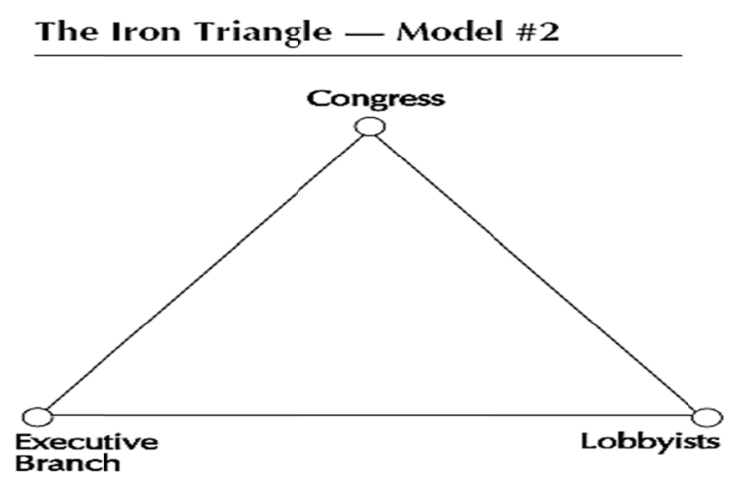

Figure 5. The iron-triangle model (Cockrel, 2002)

\subsubsection{Power Clusters Model}

In 1971, Egden used term "power network" to describe ever increasing number of factors that play an evident role is policy making. Egden introduced "Power Clusters" Model that refers to various groups influential in policy making which he calls power chords or clusters. Power clusters are generated because interested groups try to influence policies important to them independently or together. All power clusters include the same elements: executive entities, law making commissions, groups with certain interests, experts, aware public, and unaware public (Cockrel, 2002).

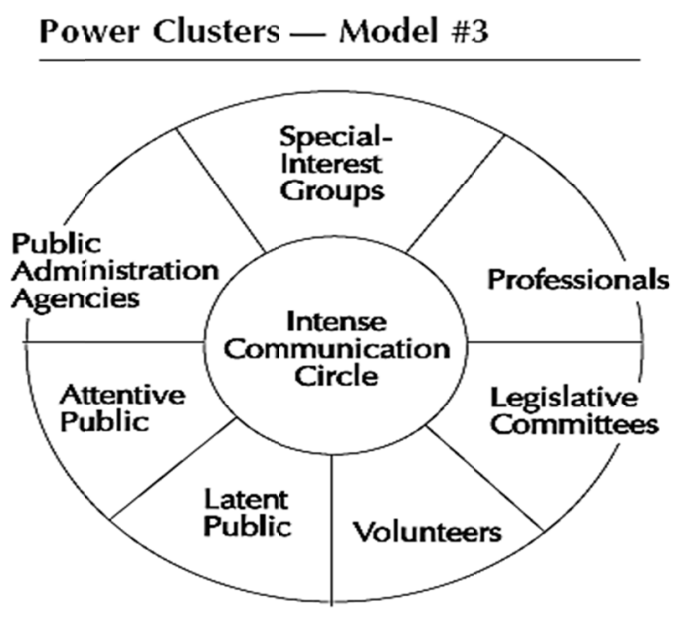

Figure 6. Power clusters model (Cockrel, 2002)

\subsubsection{King and Kingmakers Model}

In this model that can be used in every collection, power and policy are described by a pyramidal structure (Flinchbaugh, 1988). In this pyramidal model, kingmakers are at top of pyramid which has necessary 
information and financial sources for influencing or formulating required policies and they are usually hidden and unknown to public. Kings are known and selected individuals who are under control and influence of kingmakers. Active agents are in the next level and interested public are considered next. Finally, the last and most crowded level includes indifferent public.

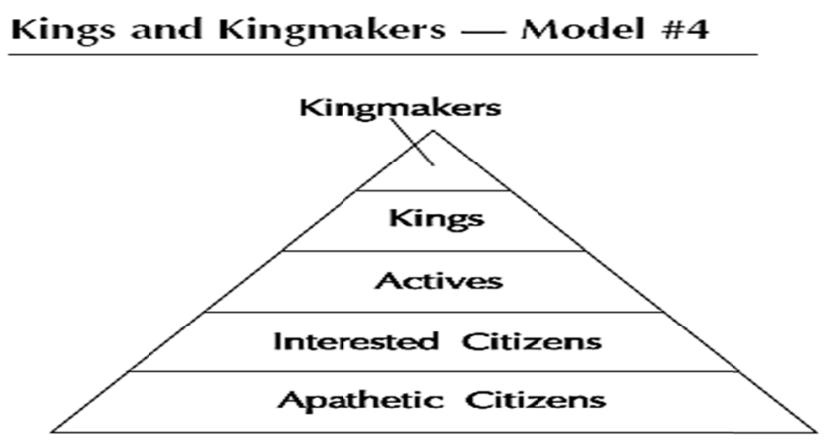

Figure 7. King and kingmakers model (Cockrel, 2002)

According to this model, agenda of public policies is provided by kingmakers and presented to king and agents. Focus of this model is on selection of few individuals from society for understanding and interpreting policy making methods. Like other elite-oriented models, this model does not state that despite public wealth is in hands of a few influential persons, many of policies formed are inconsistent with views of public. Public view of society is influenced by powerful elites and public have a little control (Cockrel, 2002).

The following table shows the most important factors that are considered as a basis of the above mentioned models:

Table 1. Effective factors in policy making models based on research background

\begin{tabular}{ll}
\hline Factors & Models \\
\hline 1-Social influence and power & $\begin{array}{l}\text { Elites Model-Group Model (Power Clusters, Iron-Triangle, King and } \\
\text { Kingmakers) }\end{array}$ \\
2-Policy making processes & $\begin{array}{l}\text { Process Model - Exploratory- Innovative Model } \\
\text { 3-External factors }\end{array}$ \\
System Model - Input-Output Model \\
5-Previous policies & Gradual Changes Model \\
Organizations & Entity Model \\
6-Cost-interest analysis & Public Selection Model - Rational Model - Satisfactory Model \\
7-Problem and need & System model- Organized Disorder Model - Social Decision Making Model \\
8-Political currents & Decision making Activities Model - Organized Disorder Model \\
\hline
\end{tabular}

\subsection{What Have Experiences of Other Countries and Regions Been?}

It is helpful to use international comparisons as part of the wider evidence base. This can contribute very positively to the policy-making process, in particular helping to guide policy-makers to new solutions to problems and new mechanisms for implementing policy and improving public service delivery. It can also provide useful evidence of what works in practice and what does not work. It is of course important to take account of social, economic and institutional differences which may require adjustment to policy solutions that work elsewhere to meet Northern Ireland circumstances.

There is a range of factors which can be helpful in identifying possible countries or regions elsewhere from which to learn: for example, regions which have successfully addressed similar social or economic issues, or 
which have geographical similarities to Iran. It is important in many areas of public service to understand the importance of factors such as settlement patterns and population density in determining what types of provision are appropriate and where we might learn lessons from elsewhere. When looking at international comparators, it is important to do so objectively. Officially published material tells the story which the promoters of a policy or project wish to tell publicly. It is important to explore beyond that: to find out what criticisms are made as well as ways in which arrangements are successful; to find out the views of service users as well as providers; to find out the extent to which a policy has actually achieved its intended outcome and whether there have been any unintended or unforeseen drawbacks or benefits; Face-to-face contact will reveal more than looking at a website alone, but given the costs associated with study visits, it is essential to do adequate research in advance to be sure that a comparator is really relevant (Office of First Minister and Deputy of First Minister in Northern Ireland, 2003).

\section{Research Methodology}

In this research, the most important factors effective in policy making models are determined by library studies. Then 11 elites were asked about these factors through questionnaire and two more factors were added according to their view about policy making in Iran. This way, the ninth factor is called "bases and principle" which suggests belief and value bases and expediencies of Islamic Republic System. The tenth factor is "top documents and laws".

After specification of ten factors mentioned, effective factors in policy making of Iran were structured using “interpretive structural equations" method and elites' views.

Interpretive Structural Modeling (ISM) is a well-established methodology for identifying relationships among specific items, which define a problem or an issue. For any complex problem under consideration, a number of factors may be related to an issue or problem. However, the direct and indirect relationships between the factors describe the situation far more accurately than the individual factor taken into isolation. Therefore, ISM develops insights into collective understandings of these relationships. ISM starts with an identification of variables, which are relevant to the problem or issue, and then extends with a group problem solving technique. Then a contextually relevant subordinate relation is chosen (Attri, Dev, \& Sharma, 2013). Having decided on the element set and the contextual relation, a structural self-interaction matrix (SSIM) is developed based on pair wise comparison of variables. In the next step, the SSIM is converted into a reachability matrix (RM) and its transitivity is checked. Once transitivity embedding is complete, a matrix model is obtained. Then, the partitioning of the elements and an extraction of the structural model called ISM is derived (Agarwal, Shankar, \& Tiwari, 2006). In this approach, a systematic application of some elementary notions of graph theory is used in such a way that theoretical, conceptual and computational leverage are exploited to explain the complex pattern of contextual relationship among a set of variables. ISM is intended for use when desired to utilize systematic and logical thinking to approach a complex issue under consideration (Ravi, Shankar, \& Tiwari, 2005). The concept of Interpretive Structural Modeling (ISM) was primary introduced by J. Warfield in 1973. Warfield proposed ISM due to evaluate the complex socioeconomic systems (Gorvett \& Liu, 2007). Sage (1997) stated that ISM approach facilitates to compel classification and direction on the complex relationships among components of a complexity of relationships among elements of a socioeconomic system. Moreover Singh and Kant (2008) interpreted the words of Interpretive Structural Modeling. According to them, ISM is interpretive as based on group's judgment and decision whether and how the system's elements are linked.

Azar (2012) believed that Interpretive Structural Modeling (ISM) approach is a method of structuring known elements. In this approach, which is in interpretive paradigm, elements are listed and structured based on elite's views. It is assumed that views of elite groups about connections between elements are basis of modeling of system or problem and have necessary validity and reliability. In this method, elite group includes 10 to 15 elites. So, in this research, 11 University professors and scholars of policy making were identified and their views were used.

\section{Analysis}

Using concept of "lead to" or "effective on", factors were assessed two by two and "structural self-interaction" matrix is formed based on the following symbols:

$\mathrm{V}$ : element $\mathrm{i}$ influences element $\mathrm{j}$.

A: element $\mathrm{j}$ influences element $\mathrm{i}$.

$\mathrm{X}$ : mutual relationship.

O: no influence. 
"Research Ability Matrix" is generated based on structural self-interaction matrix. This matrix is a square matrix whose main diameter is unit and other elements are 0 and 1 . We put 1 for $\mathrm{X}$ and $\mathrm{V}$ signs and 0 for $\mathrm{A}$ and $\mathrm{O}$ (Azar, 2012). Then, leveling table is formed which shows output elements set, input elements set and common elements set, and levels are determined based on this table. Element or elements with minimum output set and common set are put at highest level (Azar, 2012).

Table 2. Structural self-interaction matrix

\begin{tabular}{lllllllllll}
\hline Factors & 1 & 2 & 3 & 4 & 5 & 6 & 7 & 8 & 9 & 10 \\
\hline 1- Social influence and power & X & V & X & X & V & X & Y & X & A & X \\
2- Policy making processes & A & X & A & A & A & A & X & A & A & A \\
3- External factors & X & V & X & X & V & X & V & X & A & X \\
4- Previous policies & X & V & X & X & V & X & V & X & A & X \\
5-Decision maker organizations & A & V & A & A & X & A & V & A & A & A \\
6- Cost-interest analysis & X & V & X & X & V & X & V & X & A & X \\
7- Problem and need & A & X & A & A & A & A & X & A & A & A \\
8- Political currents & X & V & X & X & V & X & V & X & A & X \\
9- Principles & V & V & V & V & V & V & V & V & X & V \\
10- Top documents and laws & X & V & X & X & V & X & V & X & A & X \\
\hline
\end{tabular}

Table 3. Research ability matrix

\begin{tabular}{lllllllllll}
\hline Factors & 1 & 2 & 3 & 4 & 5 & 6 & 7 & 8 & 9 & 10 \\
\hline 1- Social influence and power & 1 & 1 & 1 & 1 & 1 & 1 & 1 & 1 & 0 & 1 \\
2- Policy making processes & 0 & 0 & 0 & 1 & 0 & 0 & 0 & 0 & 1 & 0 \\
3- External factors & 1 & 1 & 1 & 1 & 1 & 1 & 1 & 1 & 0 & 1 \\
4- Previous policies & 1 & 1 & 1 & 1 & 1 & 1 & 1 & 1 & 0 & 1 \\
5- Decision maker organizations & 0 & 1 & 0 & 0 & 1 & 0 & 1 & 0 & 0 & 0 \\
6- Cost-interest analysis & 1 & 1 & 1 & 1 & 1 & 1 & 1 & 1 & 0 & 1 \\
7- Problem and need & 0 & 1 & 0 & 0 & 0 & 0 & 1 & 0 & 0 & 0 \\
8- Political currents & 1 & 1 & 1 & 1 & 1 & 1 & 1 & 1 & 0 & 1 \\
$9-$ Principles & 1 & 1 & 1 & 1 & 1 & 1 & 1 & 1 & 1 & 1 \\
$10-$ Top documents and laws & 1 & 1 & 1 & 1 & 1 & 1 & 1 & 1 & 0 & 1 \\
\hline
\end{tabular}

Table 4. Leveling table

\begin{tabular}{lllll}
\hline Factors & Output set & Input set & Common set & Level \\
\hline 1 - Social influence and power & $1,2,3,4,5,6,7,8,10$ & $1,3,4,6,8,9,10$ & $1,3,4,6,8,10$ & Second \\
2- Policy making processes & 2,7 & $1,2,3,4,5,6,7,8,9,10$ & 2,7 & Fourth \\
3- External factors & $1,2,3,4,5,6,7,8,10$ & $1,2,3,4,5,6,7,8,10$ & $1,3,4,6,8,10$ & Second \\
4- Previous policies & $1,2,3,4,5,6,7,8,10$ & $1,3,4,6,8,9,10$ & $1,3,4,6,8,10$ & Second \\
5-Decision maker organizations & $2,5,7$ & $1,2,3,4,5,6,7,8,10$ & 5 & Third \\
6-Cost-interest analysis & $1,2,3,4,5,6,7,8,9,10$ & $1,2,3,4,6,8,9,10$ & $1,3,4,6,8,10$ & Second \\
7- Problem and need & 2,7 & $1,2,3,4,5,6,7,8,9,10$ & 2,7 & Fourth \\
8- Political currents & $1,2,3,4,5,6,7,8,10$ & $1,3,4,6,8,9,10$ & $1,3,4,6,8,10$ & Second \\
9- Principles & $1,2,3,4,5,6,7,8,9,10$ & 9 & 9 & First \\
10- Top documents and laws & $1,2,3,4,5,6,7,8,10$ & $1,3,4,6,8,9,10$ & $1,3,4,6,8,10$ & Second \\
\hline
\end{tabular}

Relationships at each level should be specified based on output and input sets. Also, only direct relationships of elements at K and K-1 levels are shown. Therefore, we have a hierarchical technique in which relationships of elements of non-consecutive levels are guaranteed through indirect relationships of elements in levels (Azar, 2012). According to results of this research, combined model of factors influential in Iran policy making can be considered as follows: 


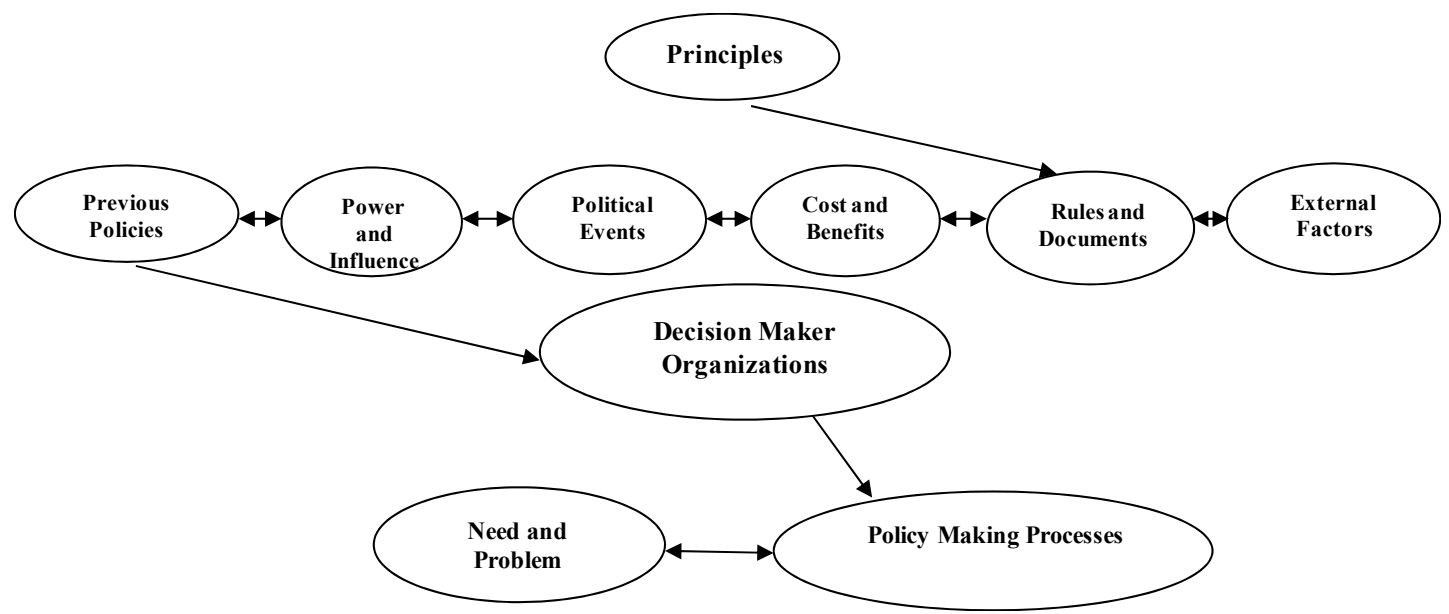

Figure 8. Combined model of factors influential in Iran's policy making

Based on this model, element "bases and principle" is expressed at first level as a factor that influences all factors but is not influenced by any factor. At next level, we have "cost-benefit analysis", "top documents and laws", "external factors", "political currents", "social influence and power" and "previous policies" all of which have interconnections with each other which means that each of these factors influences others and is influenced by others. At next level, we only have "decision maker organizations" that is influenced by all factors of the former two levels. Finally, the last level includes two factors "policy making process" and "problem and need" that are influenced by all factors of former levels and influence each other. For simplifying this model, effect of each level on next level is presented only by direct connection of the two factors but, since elements of the second and fourth levels influence each other, all of effects can be observed by indirect connection.

\section{Conclusions}

The most important factors effective in policy making models can be identified by evaluating these models. However, policy making conditions in Iran is also influenced by Islamic, value and belief principles such as Velayat-e-Faghih, seeking justice etc. as well as governmental principles such as fighting colonialism and dictatorship. These factors make decision making conditions of Iran radically different from common systems of world. Considering this unique characteristic and necessity of a comprehensive evaluation of this issue and in order to increase applicability of proposed models, it is attempted in this research to identify effective factors, structure these factors and obtain combined model of policy making in Islamic Republic of Iran.

As literature review indicates, available models approach policy making issue from their own point of views that can be divided into two groups: "focus on decision maker" and "focus on decision making manner". Members of each group evaluate the issue based on a certain aspect. Considering the power and benefits of this approach, as mentioned before, there must be a comprehensive view in this particular area for application in specific cases and this research was an attempt to do so.

In the structural model obtained, policy making is based on principles of Islamic Government. This means that all decisions and policies in Islamic Republic of Iran should be made based on belief, value and governmental principles and do not have any contrast with them under any conditions. In certain conditions after Islamic Revolution in Region and world, environmental and external factors had an important role in decision making and by adapting to principles, are considered one of the most essential factors of decision making in Iran. Cost-benefit analysis, political currents in society (such as epozosion groups etc.), previous decisions, and social influence and power (such as monopoly power, social influence and power groups determine and direct political currents) also influence policy making. These factors are influenced by principles and by each other and at the same time influence other factors. For example, mutual relation of two factors "social influence and power" and "political currents" can be justified as follows: social influence and power determine and direct political currents and, on the other hand, political currents influence and change amount and manner of power and social influence.

At next level, decision maker organizations, such as ministries and councils, are effective in policy making and according to relations obtained, these entities are influenced by all factors of previous levels. Finally, factors of the most influenced level are "policy making processes" and "problem and need" which means that these two 
factors are influenced by all previous factors and have interaction. This way, it can be said that most policies and decisions of the country are results of structural relationships mentioned here.

According to general classification of various policy making models, the structural model obtained is more converged to the groups based on "decision making manner" than "decision maker" and considering the leveling performed in this model, most convergence is observed with rational model (range of rational to satisfactory models) and system model (due to focus on environmental factors).

\section{References}

Agarwal, A., Shankar, R., \& Tiwari, M. K. (2006). Modeling agility of supply chain. Industrial Marketing Management, 36, 443-457. http://dx.doi.org/10.1016/j.indmarman.2005.12.004

Alvani, S. M., \& Sharif zadeh, F. (2008). The Public Policy Process (6th ed.). AllamehTabatabaei University Press, Tehran, Iran.

Alvi, H., \& Gvosdev, N. K. (2010). Case studies in policy making (12th ed). Naval War College, Newport: USA.

Attri, R., Dev, N., \& Sharma, V. (2013). Interpretive Structural Modeling (ISM) approach: An Overview. Research Journal of Management Sciences, 2(2), 3-8.

Azar, A. (2012). Advanced statistical methods in management. Tehran, Iran: Samt press.

Baumfeld, L., Hummelbrunner, R., Lukesch, R., Regionalbearatung, O., \& Huber, W. (2002). Reforming structural funds: How to reconcile complexity with simplification? Proposals for a new model of policy making and governance considering the peculiarities of social system, Australian federal chancellery.

Birkland, T. M. (2011). An Introduction to the policy process, Theories, Concepts, and Models of Public Policy-Making, M. E. Sharped Press, $3^{\text {rd }}$ Ed.

Boer, A., Engers, T., \& Sileno, G. (2011). A problem solving model for regulatory policy making, The 24th International Conference on Legal Knowledge and Information Systems (JURIX 2011). University of Vienna, Vienna, Austria.

Boulanger, P., \& Bre'chet, T. (2005). METHODS Models for policy-making in sustainable development: The state of the art and perspectives for research. Ecological Economics, 55, 337-350. http://dx.doi.org/10.1016/j.ecolecon.2005.07.033

Bullock, H., Mountford, J., \& Stanley, R. (2001). Better policy- making, Center for management and policy studies. Cabinet Office, London.

Clift, S. (2003). E-Democracy, E-Governance and Public Net-Work. Retrieved from http://www.publicus.net/articles/edempublicnetwork.html

Cockrel, J. (2002). Public Policy making in America, Cooperative Extension Service. University of Kentucky.

Colleti, D., \& Murchison, S. (2002). Models in policy-making, bank of Canada review (pp. 19-26). Summer.

Edwards, P. N. (1996). Global Comprehensive Models in politics and Policy making. Climatic Change, 32, 149161. http://dx.doi.org/10.1007/BF00143706

Flinchbaugh, B. L. (1988). How to Do Policy Education in Working with Our Publics, Module 6: Education for Public Decisions.

Gholipour, R. (2008). Drganizational Decision-Making and Public Policy. Tehran, Iran: Samt Press.

Howlett, M., Ramesh, M., \& perl, A. (2009). Studying Public policy, Policy Cycles \& Policy subsystems $\left(3^{\text {rd }}\right.$ Ed.). Oxford University Press.

Jahanshahi, A. A., Rezaei, M., Nawaser, Kh., Ranjbar, V., \& Pitamber, B. K. (2012). Analyzing the Effects of Electronic Commerce on Organizational Performance: Evidence from Small and Medium Enterprise. African Journal of Business Management, 6(15), 6486-6496.

Keskinen, A., \& Kuosa, T. (2005). Introduction to Citizen oriented Decision Making. New e-Democracy Tools for the 21 st Century. In Marshall, Stewart \& Taylor, Wal \& Yu Xinghuo (Eds.), Encyclopedia of Developing Regional Communities with Information and Communication Technology. Idea Group Reference, Idea Group Inc., USA. http://dx.doi.org/10.4018/978-1-59140-575-7.ch016

Leach, W. D., \& Sabatier, P. (2005). To Trust an Adversary: Integrating Rational and Psychological Models of Collaborative Policymaking. American Political Science Review, 99(4), 491-503. http://dx.doi.org/10.1017/S000305540505183X 
Nawaser Kh, Khaksar, S. M. S., Shakhsian, F., \& Jahanshahi, A. A. (2011). Motivational and Legal Barriers of Entrepreneurship Development in Iran. International Journal of Business and Management, 6(6), 112-118. http://dx.doi.org/10.5539/ijbm.v6n11p112

Office of First Minister and Deputy of First Minister in Northern Ireland. (2003). A Practical Guide to Policy Making in Northern Ireland. Retrieved from www.ofmdfmni.gov.uk/practical-guide-policy-making.pdf

Osimo, D. (2011). Benchmarking e- government, policy-making a refined model. Retrieved from http://egov20.wordpress.com/2011/07/14/policy-making-2-0-a-refined-model/

Rabiee, M. R., \& Givrian, H. (2005). Decision-making and public policy. Tehran, Iran: Yekan Press.

Ravi, V., Shankar, R., \& Tiwari, M. K. (2005). Productivity improvement of a computer hardware supply chain. International Journal of Production and Performance Measurement, 54(4), 239-255. http://dx.doi.org/10.1108/17410400510593802

Rick Gorvett, R., \& Liu, N. (2007). Using Interpretive Structural Modeling to Identify and Quantify Interactive Risks.

Sabatier, P. (2007). Theories of the Policy Process. Westview Press, United States of America.

Sage, A. (1977). Interpretive Structural Modeling: Methodology for Large-scale Systems (pp. 91-164). New York, NY: McGraw Hill.

Singh, M., \& Kant, R. (2008). Knowledge management barriers: An interpretive structural modeling approach. International Journal of Management Science and Engineering Management, 3, 141-150.

Tickell, C. (2008). A new look at the interaction of scientific models and policymaking. James Martin $21^{\text {st }}$ Century School, University of Oxford.

Turner, S. (2008). Expertise and the Process of Policy-Making: The EU's New Model of Legitimacy. Building Civil Society and Democracy in New Europe.

Vahid, M. (2007). A Discussion on Cultural Policy. Journal of Politics, Journal of the Faculty of Law and Political Sciences, 37(3), 287-306.

Weible, C., Sabatier, P., \& Lubell, M. (2004). A Comparison of a Collaborative and Top-Down Approach to the Use of Science in Policy: Establishing Marine Protected Areas in California. The Policy Studies Journal, 32(2). http://dx.doi.org/10.1111/j.1541-0072.2004.00060.x

Wyner, A., \& Benn, N. (2011). Modeling Policy- making, in conjunction with the 24th international conference on legal knowledge and information systems, Vienna, Austria.

\section{Copyrights}

Copyright for this article is retained by the author(s), with first publication rights granted to the journal.

This is an open-access article distributed under the terms and conditions of the Creative Commons Attribution license (http://creativecommons.org/licenses/by/3.0/). 